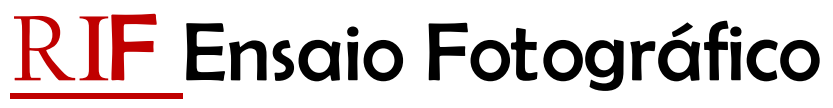

\author{
DOI - 10.5212/RIF.v.19.i43.0019
}

\section{Sertão Ocre: memórias do presente}

Fotos e texto: Antonio Leonardo de Sousa Reis ${ }^{1}$

Em Sertão Ocre, temas como memórias, vida no interior e simplicidade são abordados e construídos narrativamente. O referido ensaio fotográfico possibilita a imersão em um ambiente que é desvalorizado e renegado por muitos que não conhecem as vivências e a valorização do que se toma como tradição. Em meio a um crescente ambiente virtual, o sertão do interior do Ceará resiste e segue com uma vida rotineira após décadas de modernização e ampliação de mecanismos eletrônicos. A tecnologia deixada de lado leva a uma conexão com a natureza e os sentidos e padrões que estão sendo ameaçados de desaparecerem com a nova geração. O que resta são costumes e tradições enraizadas desde cedo por familiares e que são passadas de geração em geração. Evidenciar as simplicidades e as belezas que o sertão ainda possui é o foco deste ensaio, além de mostrar o quanto a repetição de cores e o tempo estão presentes.

A palavra sertão tem servido, em Portugal e no Brasil, para designar o "incerto",
o "desconhecido", o "Iongínquo", o "interior", o "inculto" (terras não cultivadas
e de gente grosseira), numa perspectiva de oposição ao ponto de vista do
observador, que se vê sempre no "certo", no "conhecido", no "próximo", no
"litoral", no "culto", isto é, num lugar privilegiado - na "civilização". (TELES,
2011, p.43)

A "incerteza" do que temos no interior é o que traz a curiosidade e vontade de explorar o que é desenvolvido, vivenciado e passado de geração em geração. São narrativas próprias de um tempo que passa mais devagar, onde as divergências de idades estão surgindo e a tecnologia tomando o seu espaço. A memória muitas vezes pode dizer quem fomos em um passado sempre diferente do que se encontramos no presente. A partir da oralidade, narrativas de memórias são traçadas possibilitando um percurso onde a história do indivíduo também faz parte de uma história maior e coletiva.

\footnotetext{
${ }^{1}$ Graduando em Comunicação Social - Habilitação em Jornalismo na Universidade Federal do Ceará - UFC; Pesquisador em comunicação comuni tária, cultura popular e arte cearense; Fotógrafo de cotidianos invisibilizados. Correio el etrônico: antonioleonardo87@gmail.com | leonardoreis@alu.ufc.br
} 


\section{RIF, Ponta Grossa/ PR Volume 19, Número 43, p.342-349, jul./dez. 2021}

O ocre é uma vasta possibilidade de cores terrosas produzidas pela natureza que são fortemente presentes em um ambiente em que a modernização ainda caminha em passos compassados. Tons de marrom e verde são destaques e a composição de cena é um ponto importante para a contextualização da narrativa. As fotos foram registradas com uma câmera semiprofissional no município de Quixadá-CE, região sertão-central do Ceará. Para considerações da importância imagética, a natureza também é uma forma de comunicação do homem e de sua relação com o ambiente. "O sertanejo é, antes de tudo, um forte" (CUNHA, 2003), representação que permanece em tempos incertos.

No presente ensaio as fotos foram tiradas ao nascer ou no pôr do sol para que a iluminação ajudasse na composição de luz e no contexto do ocre. Fotos não editadas, apenas com correção de enquadramento.

Foto 01: “O terreno árido"

(Distrito de Santa Paz, Quixadá-CE - outubro/2020)

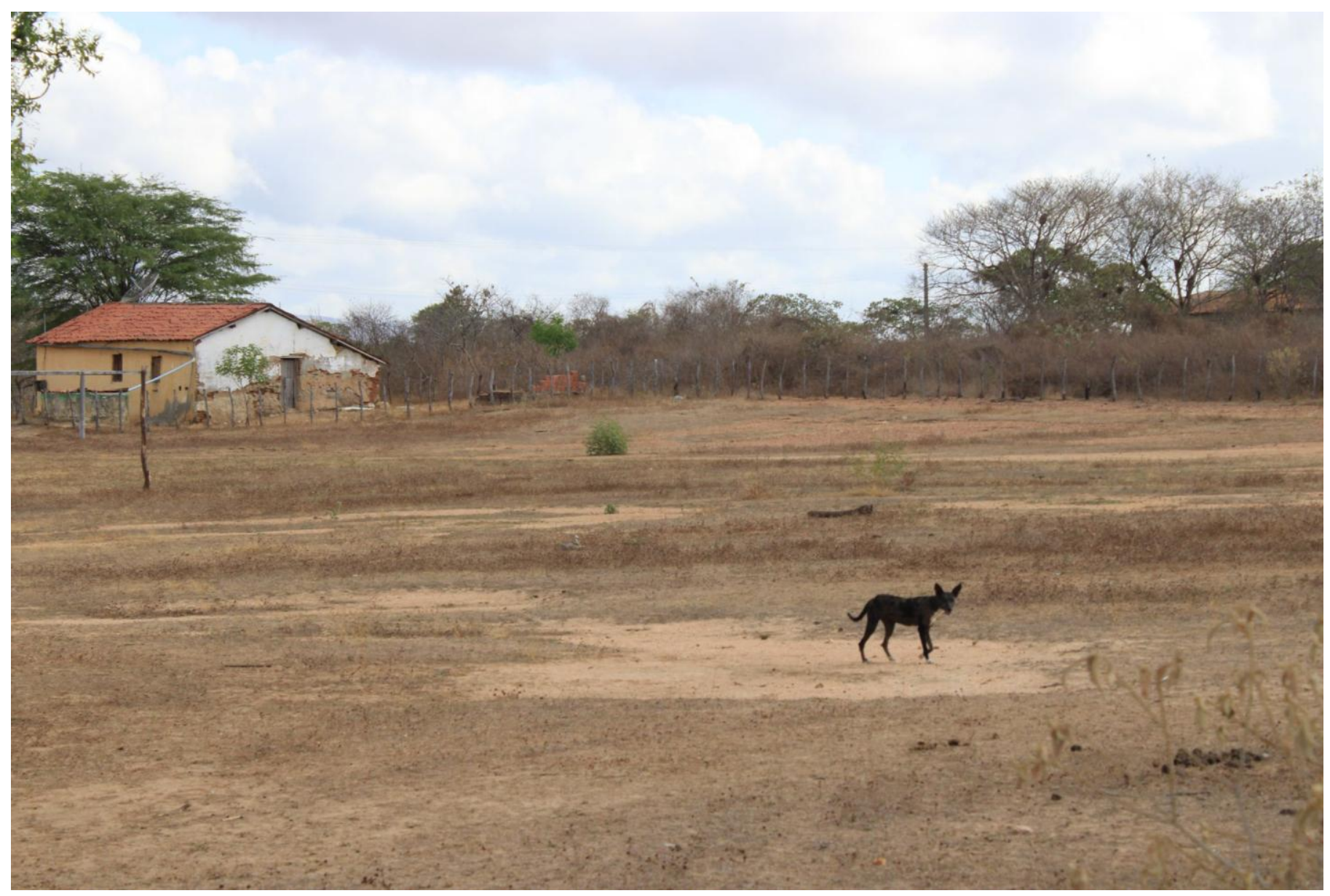


RIF, Ponta Grossa/ PR Volume 19, Número 43, p.342-349, jul./dez. 2021

Foto 02: "Naturalmente morada"

(Distrito de Santa Paz, Quixadá-CE - outubro/2020)

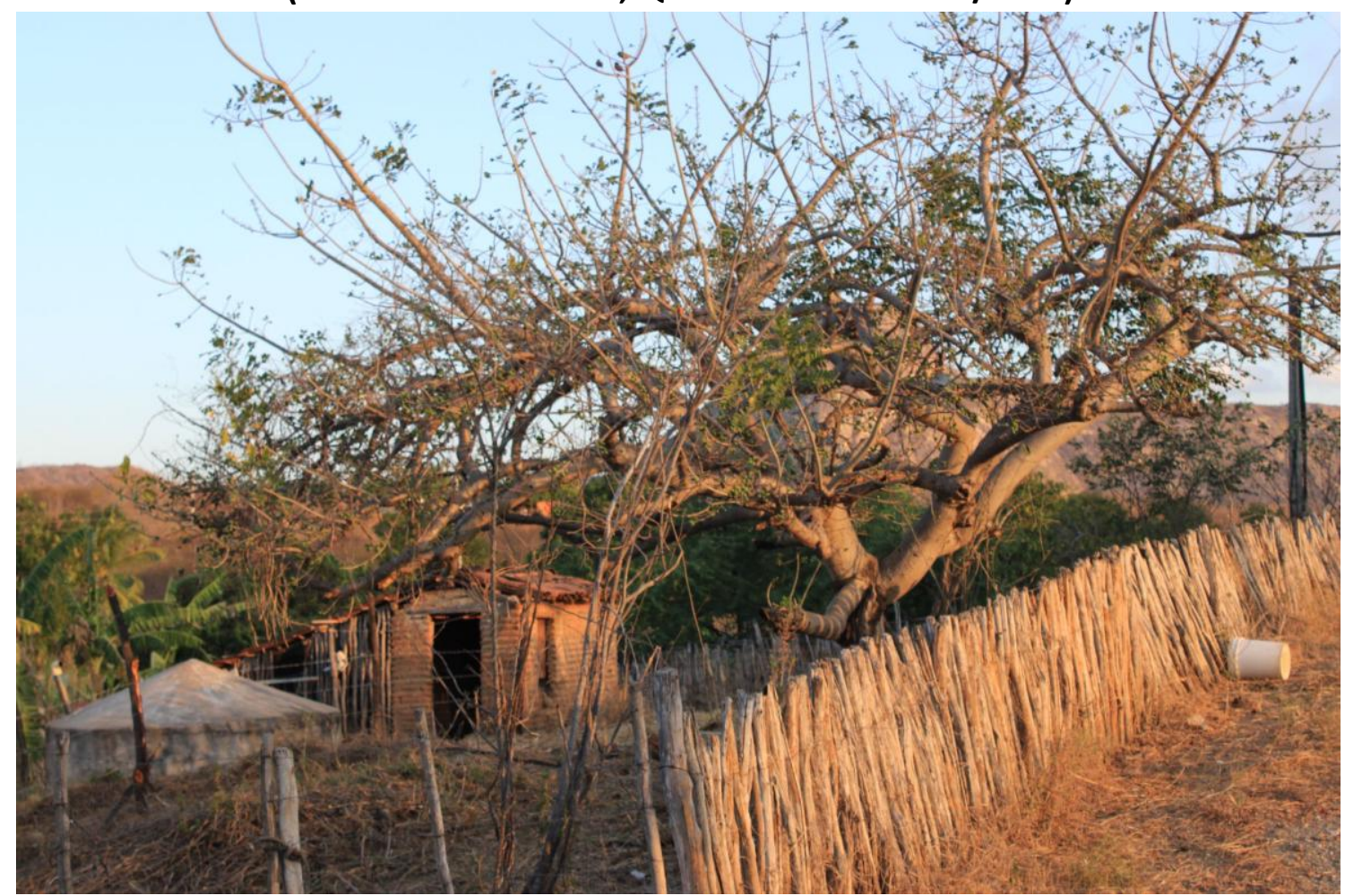

Foto 03: "Casarão"

(Região do Açude do Cedro, Quixadá-CE - outubro/2020)

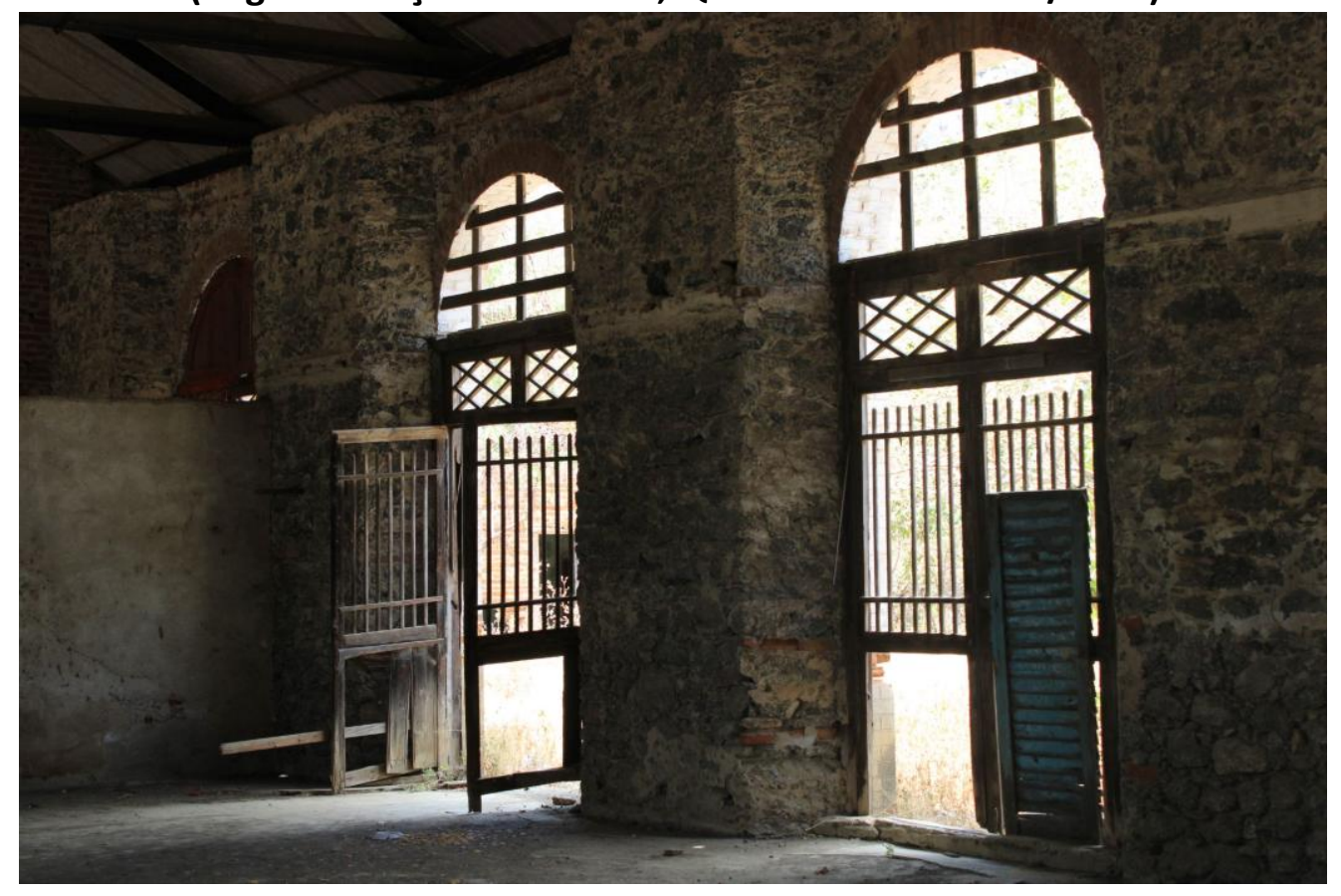

344 | Sertão Ocre: memórias do presente 
RIF, Ponta Grossa/ PR Volume 19, Número 43, p.342-349, jul./dez. 2021

Foto 04: "Brechadá"

(Distrito de Santa Paz, Quixadá-CE - outubro/2020)

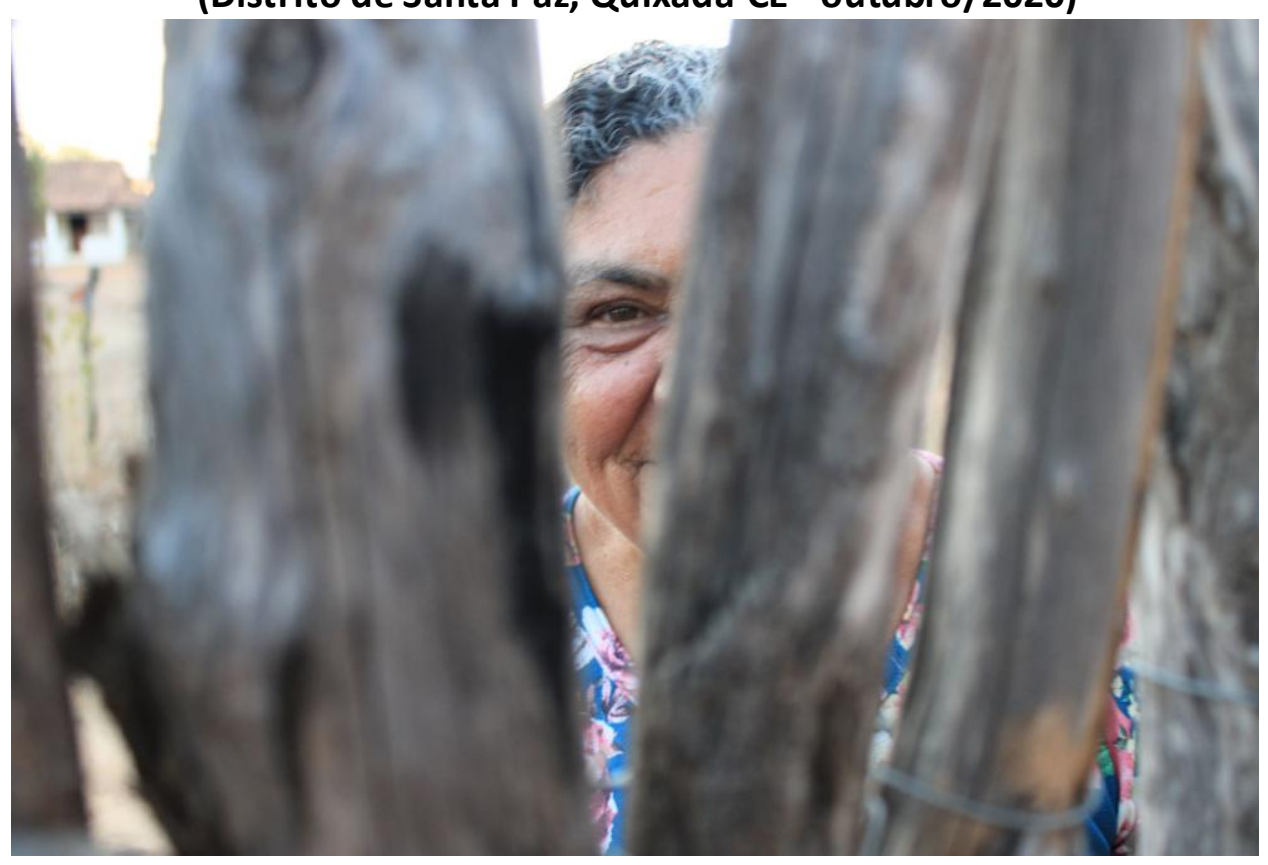

Foto 05: "Resquícios"

(Distrito de Alvoredo, Quixadá-CE - outubro/2020)

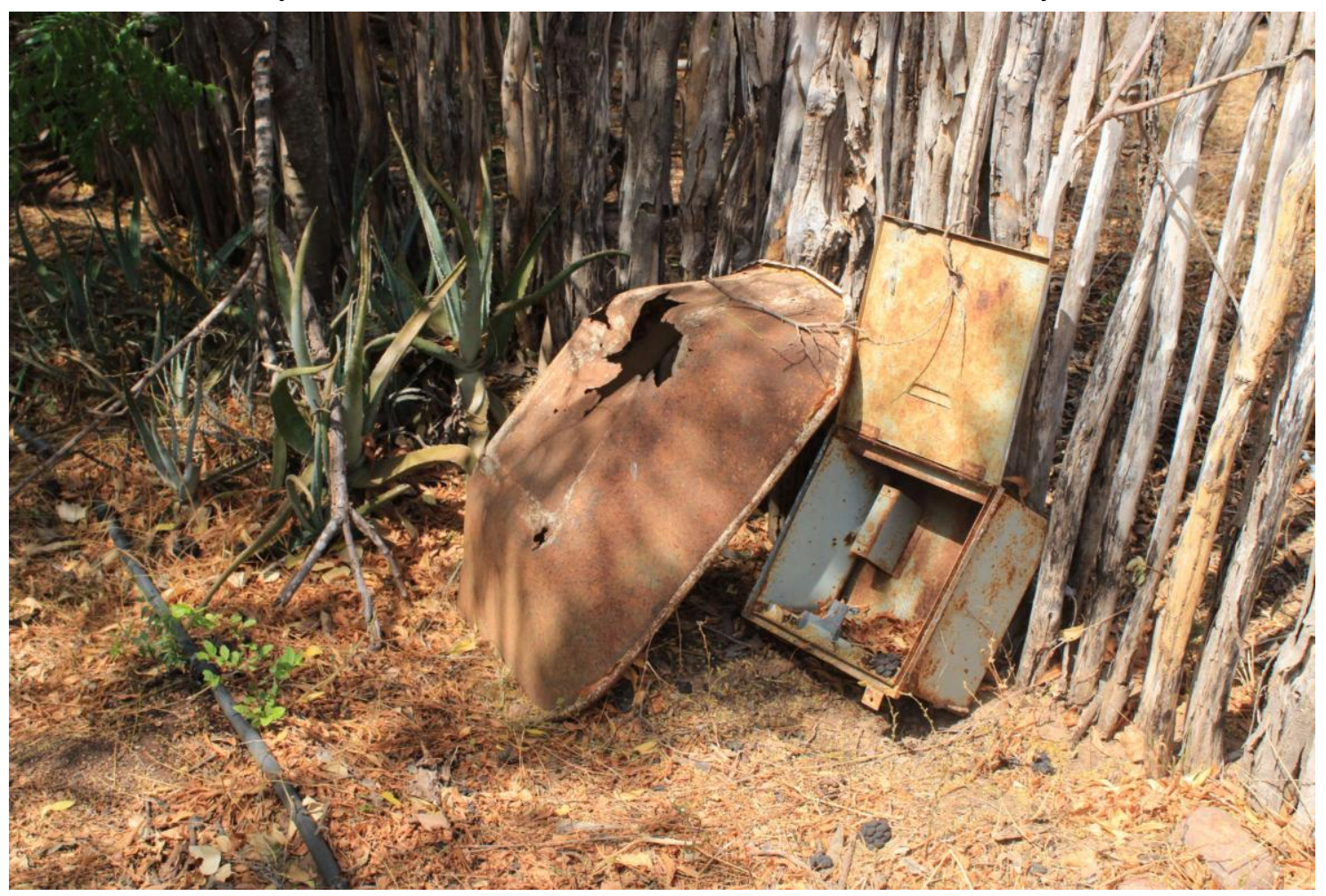

345 | Sertão Ocre: memórias do presente 
RIF, Ponta Grossa/ PR Volume 19, Número 43, p.342-349, jul./dez. 2021

Foto 06: "Sobras da colheita"

(Distrito de Alvoredo, Quixadá-CE - outubro/2020)

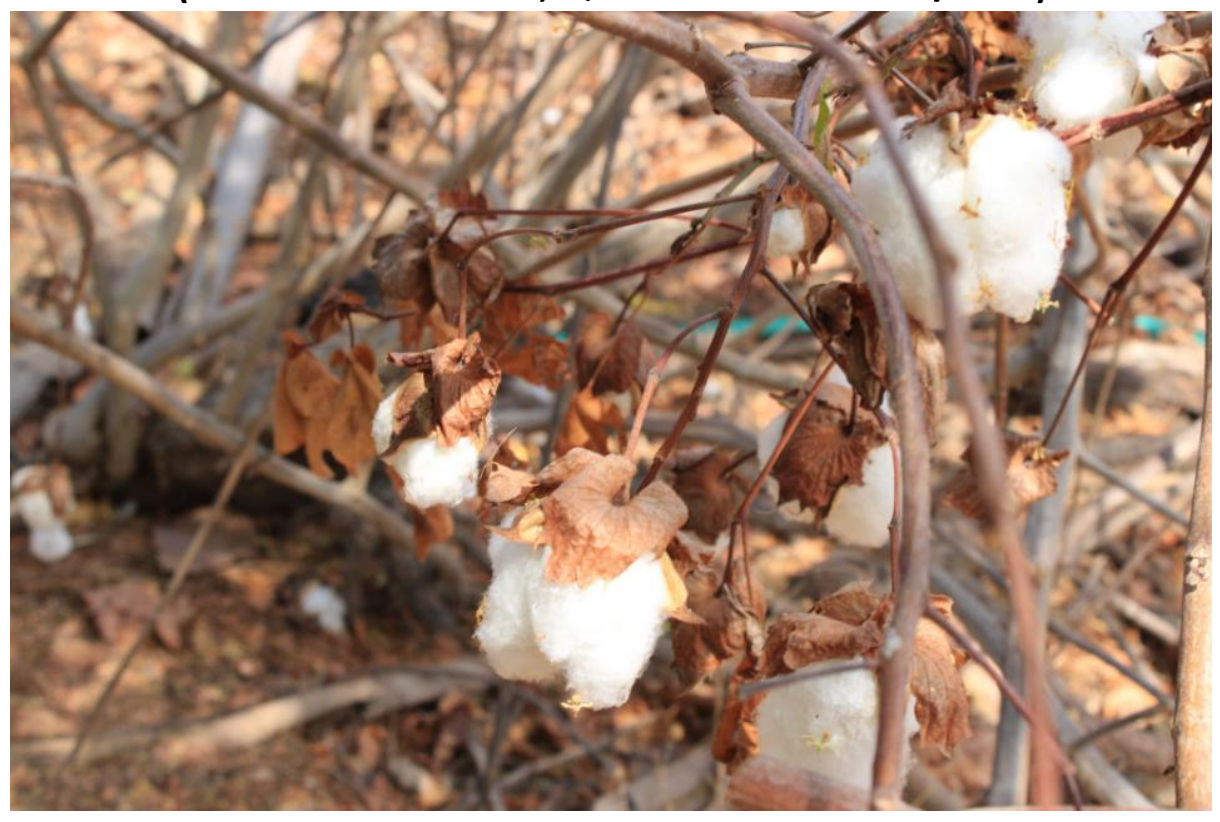

Foto 07: “Bacurin"

(Distrito de Alvoredo, Quixadá-CE - outubro/2020)

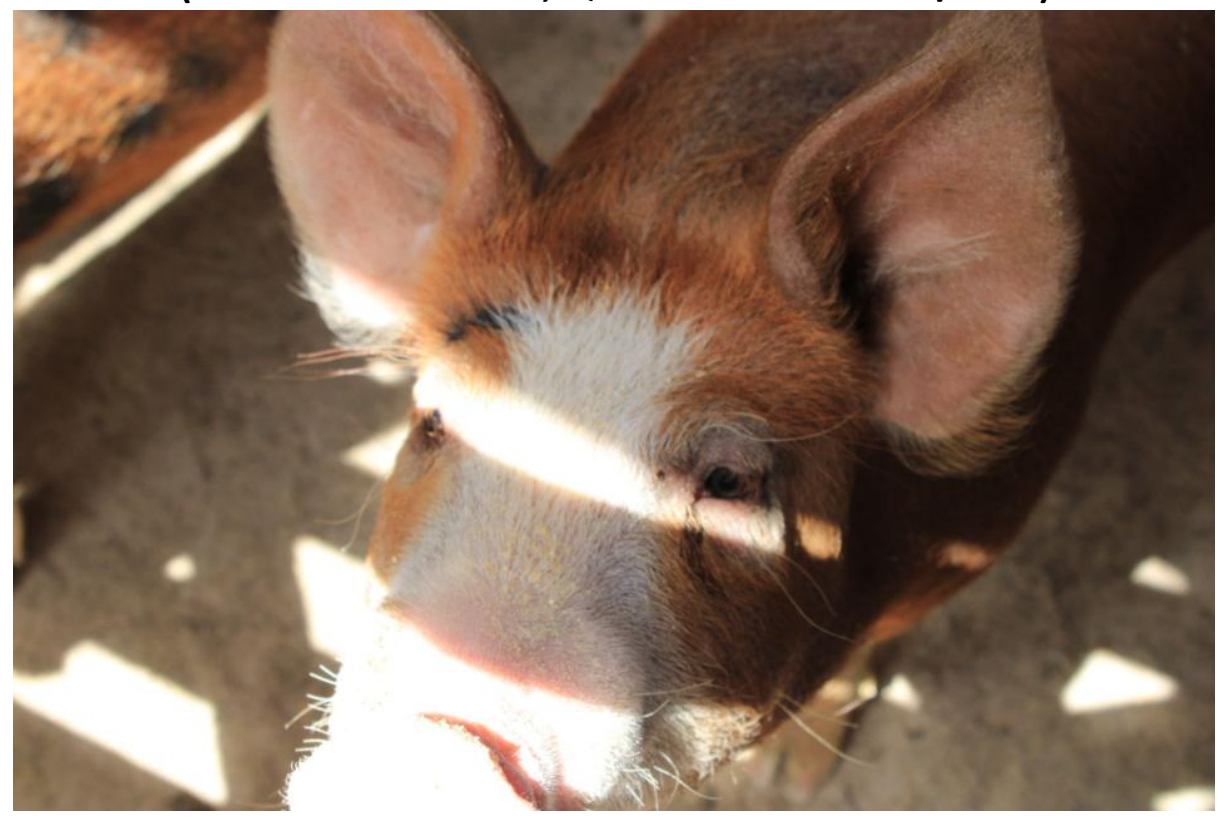


RIF, Ponta Grossa/ PR Volume 19, Número 43, p.342-349, jul./dez. 2021

Foto 08: "De cada dia"

(Distrito de Serra do Padre, Quixadá-CE - outubro/2020)

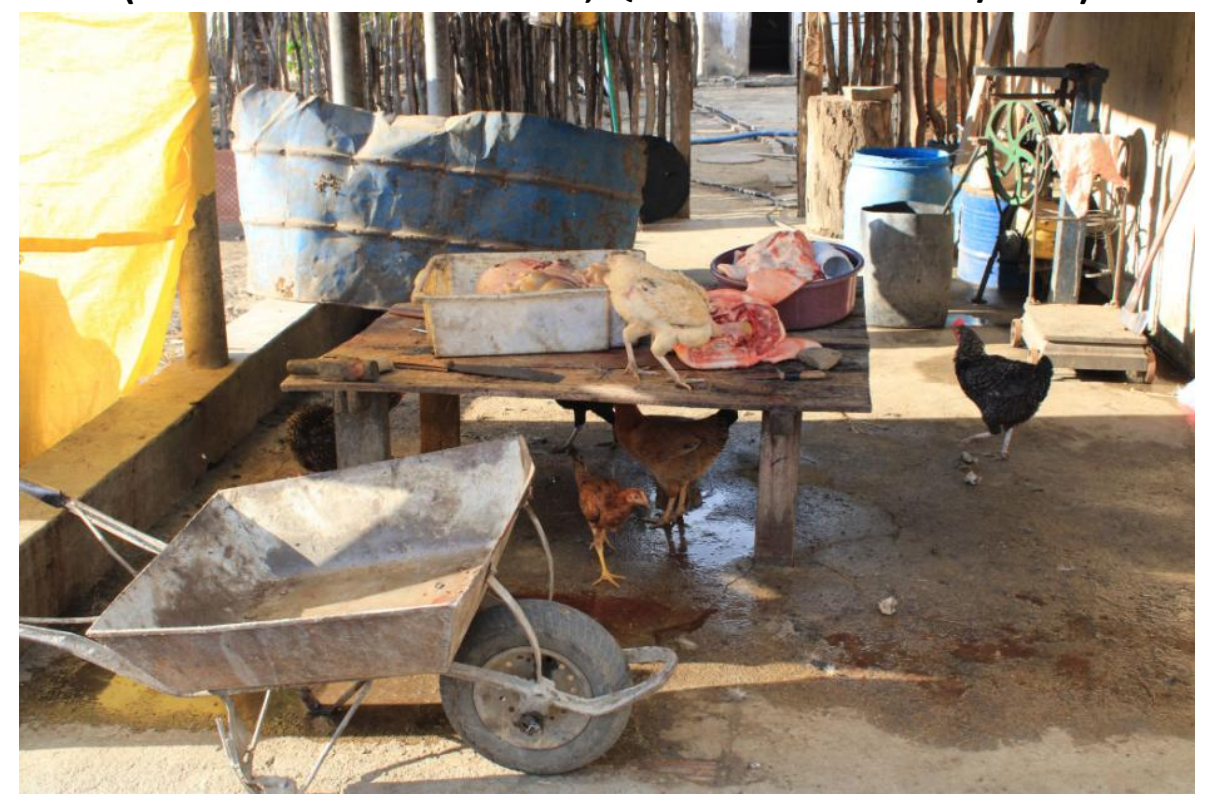

Foto 09: “A entrega”

(Distrito de Serra do Padre, Quixadá-CE - outubro/2020)

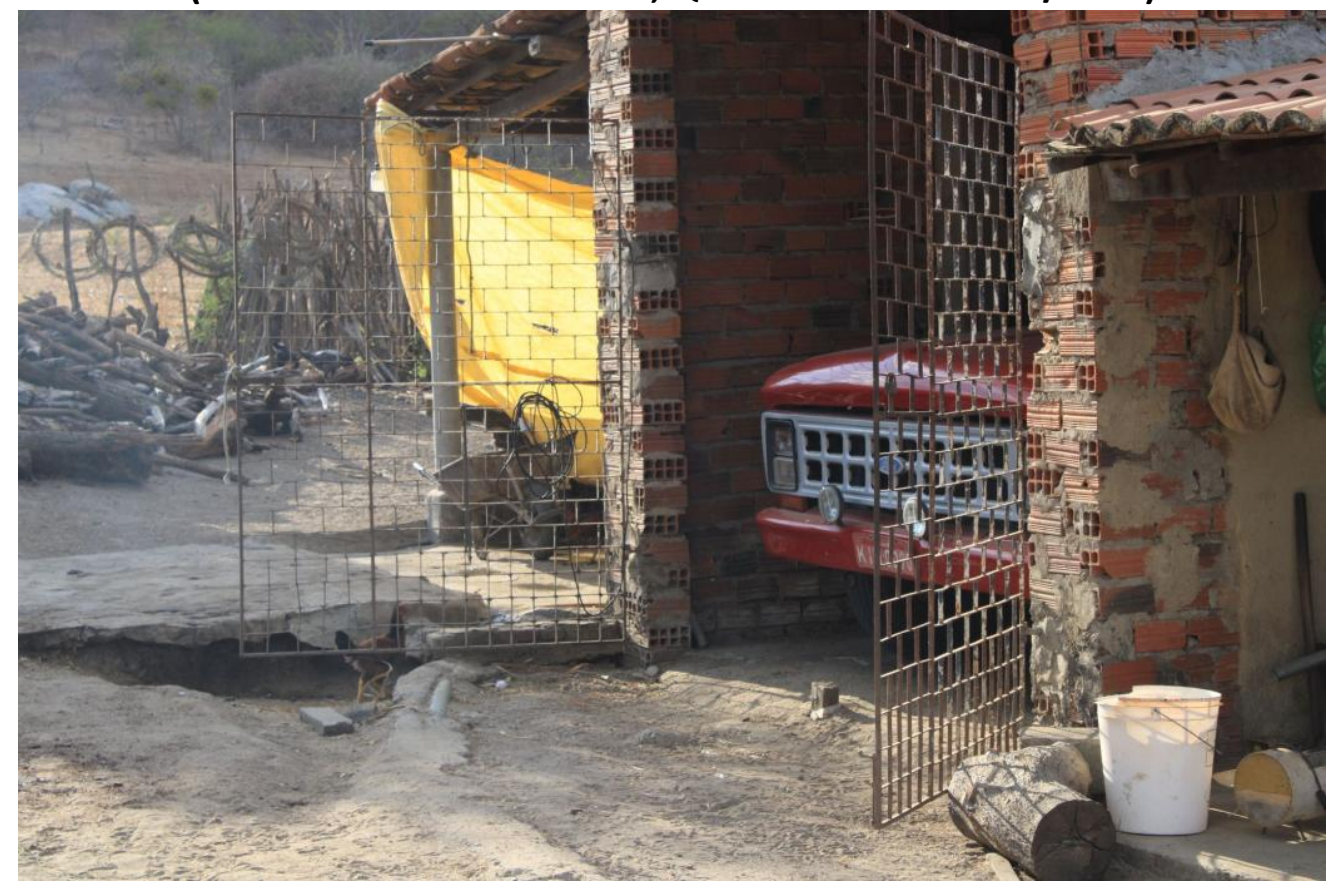

347 | Sertão Ocre: memórias do presente 
RIF, Ponta Grossa/ PR Volume 19, Número 43, p.342-349, jul./dez. 2021

Foto 10: "Rebanho e ordenha"

(Distrito de Serra do Padre, Quixadá-CE - outubro/2020)

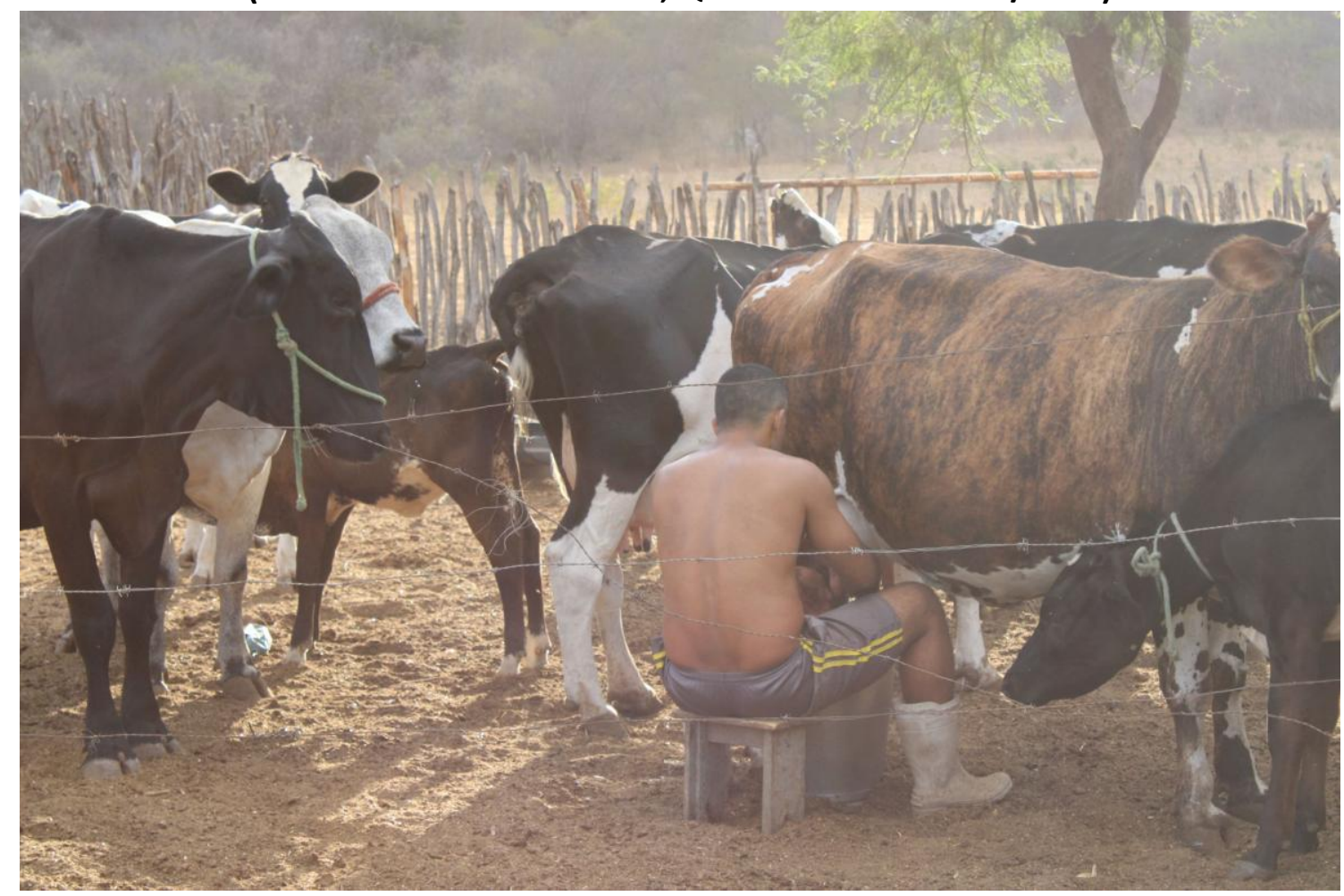

Foto 11: "Porta espelhada"

(Região do Açude do Cedro, Quixadá-CE - outubro/2020)

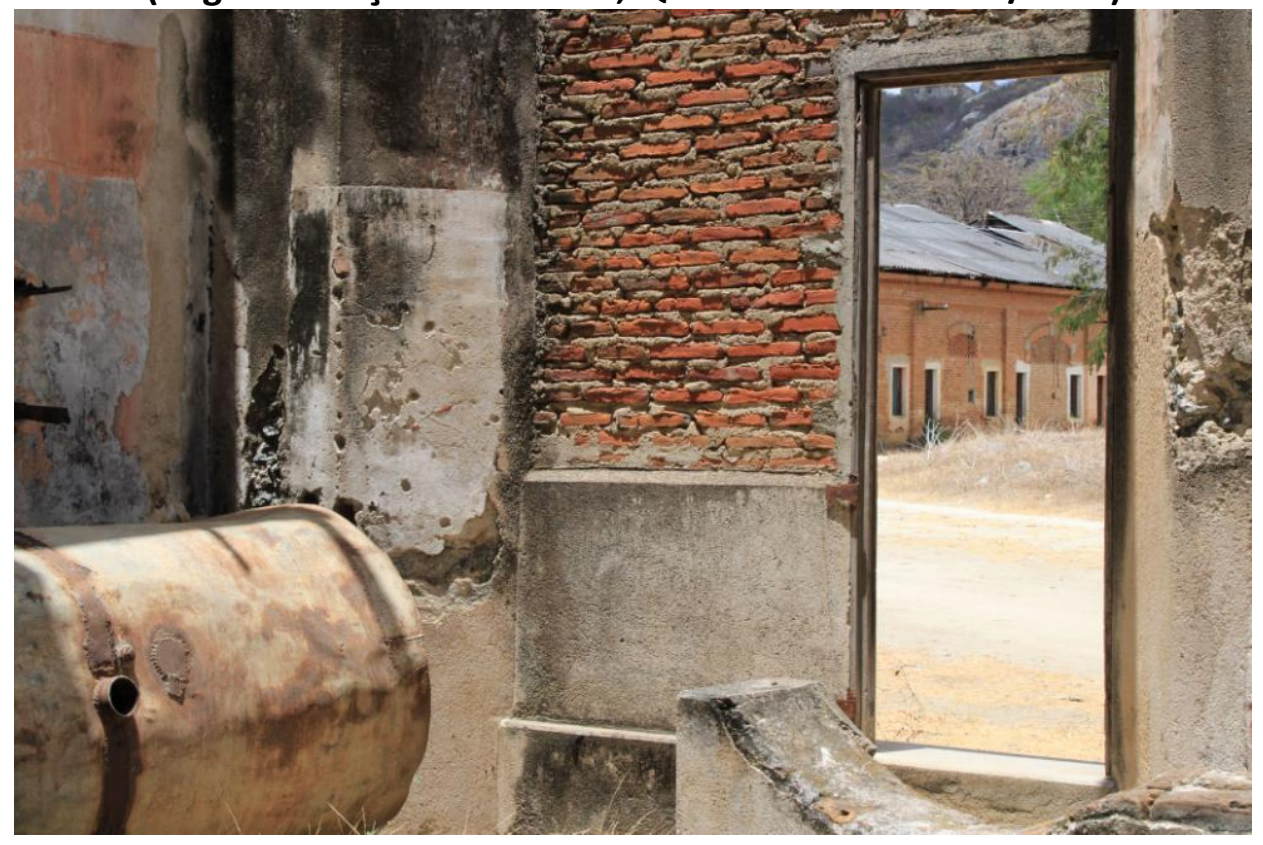

348 | Sertão Ocre: memórias do presente 
RIF, Ponta Grossa/ PR Volume 19, Número 43, p.342-349, jul./dez. 2021

Foto 12: "A esperança do novo"

(Distrito de Santa Paz, Quixadá-CE - outubro/2020)

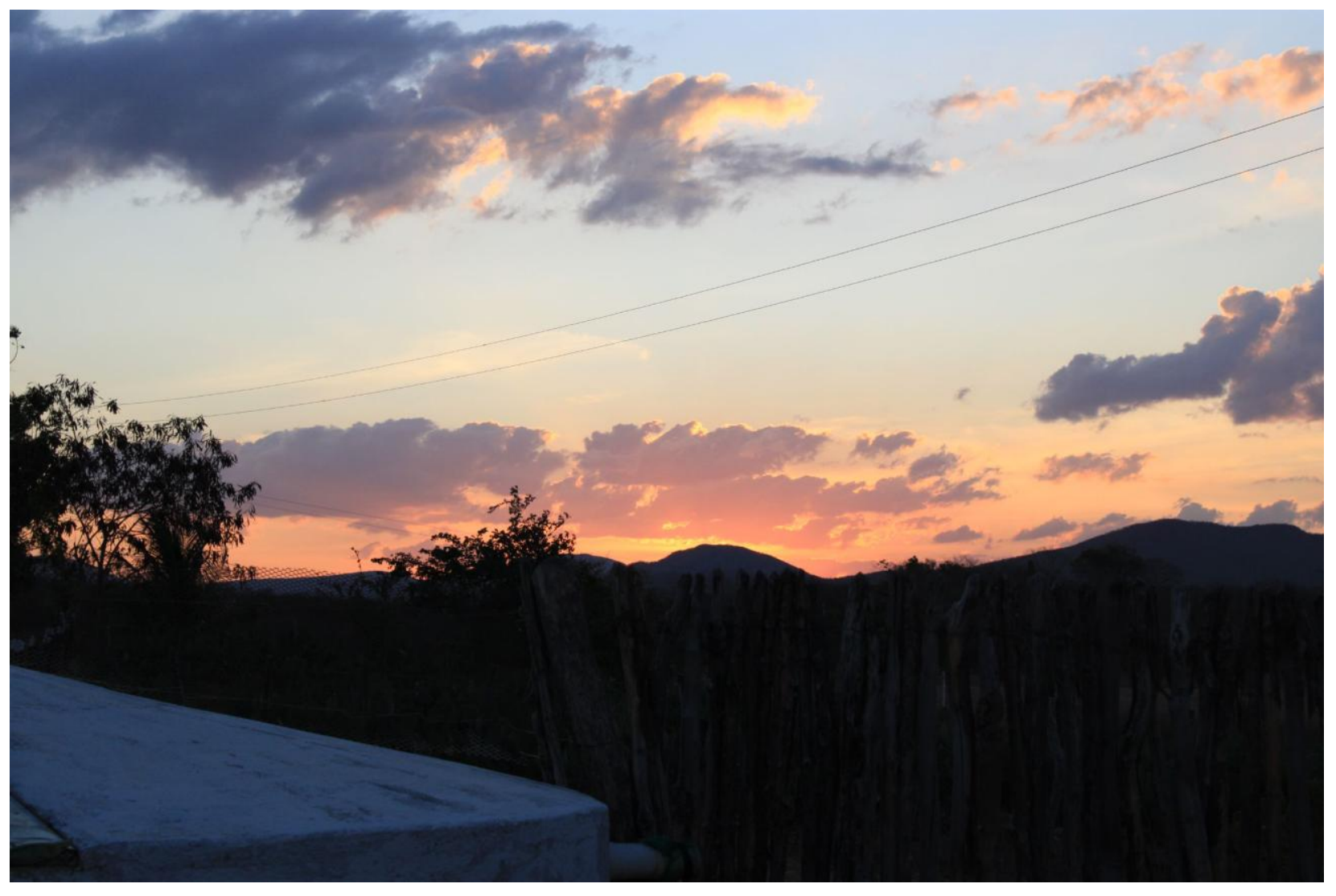

Referências

CUNHA, Euclides da. Os Sertões. Rio de Janeiro: Ediouro, 2003.

TELES, Gilberto M. O lu(g)ar dos sertões. Periódicos UFMS, Mato Grosso do Sul, 2009. 